\title{
CANTO DE SIRENA DE GREGORIO MARTÍNEZ Y LA ESTÉTICA DE LA NOVELA POSTERIOR AL "BOOM"
}

\author{
CANTO DE SIRENA BY GREGORIO MARTÍNEZ AND \\ THE AESTHETICS OF THE NOVEL AFTER THE “BOOM”
}

\author{
Jorge Valenzuela Garcés* \\ Universidad San Ignacio de Loyola. Perú \\ Universidad Nacional Mayor de San Marcos. Lima \\ jorgevalenzuela4@hotmail.com
}

\begin{abstract}
Resumen: En este artículo se analiza la novela Canto de sirena del peruano Gregorio Martínez (1942-2017) a partir de la estética que nutrió a los escritores del llamado postboom de la narrativa hispanoamericana. Nuestro propósito es observar, en la novela mencionada, la utilización de ciertos presupuestos, principios y estrategias que se generaron en respuesta a la estética del "boom" y al proyecto de la novela total que se configuró como su ideal novelístico. Empleamos el marco teórico y las ideas planteadas por Ángel Rama (1981), Antonio Skármeta (1984).
\end{abstract}

Palabras clave: Canto de sirena, Gregorio Martínez, novela latinoamericana, postboom.

\begin{abstract}
In this article, the novel Canto de sirena by peruvian writer Gregorio Martínez (1942-2017) is analyzed based on the aesthetics that nurtured postboom writers. Our purpose is to observe the use of certain assumptions, principles and strategies that were generated for the new novelist in response to the aesthetics of the "boom" and the project of the total novel that became his novelistic ideal. We use the theoretical framework and the ideas put forward by Ángel Rama (1981) and Antonio Skármeta (1984) around the new generation of Latin American narrators.
\end{abstract}

Keywords: Canto de sirena, Gregorio Martínez, Latin American novel, postboom.

Recibido: 05/05/2018. Aceptado: 22/11/2018.

* Es profesor principal del Departamento de Literatura de la Facultad de Letras de la Universidad Nacional Mayor de San Marcos de Lima. 


\section{Introducción}

partir de los años setenta se puede advertir, con mayor claridad, en la obra de los nuevos narradores peruanos, un intento diferenciador con respecto a la de los narradores pertenecientes al "boom”. Este alejamiento, estimulado por la relación creativa que los nuevos establecen con los recursos expresivos y las estrategias comunicacionales de las diversas conformaciones textuales provenientes de los sistemas de comunicación de los media, es clave para entender su poética y sus logros. En efecto, los nuevos narradores exploran en la realidad con las armas del periodismo, el cine y los medios audiovisuales, en un intento de dar cuenta de la realidad desde una dimensión marcada por la urgencia del presente y por la necesidad de referir sus universos desde una perspectiva menos pública, pero no por ello menos política. Esta tendencia, que es central para entender el cambio que se opera en la novela, afecta a la mayor parte de la producción de la época.

A este diálogo entre novela y medios de comunicación debe añadirse un afán introspectivo, cuya consecuencia más notoria fue la producción de una novelística menos ambiciosa en sus pretensiones totalizantes que las novelas del boom, pero abierta a la manifestación de universos marcados a fuego por la marginalidad y la histórica invisibilidad, como sucede en el caso de la novela objeto de nuestro análisis.

En efecto, en este período se abandona el intento por dotar a la novela de una visión integradora del conglomerado social y hasta latinoamericano $\mathrm{y}$, por consiguiente, se renuncia a la obsesiva idea de la novela total, para volver a una novela más concentrada en la reivindicación de sectores o espacios marginales no antes representados, sin abandonar, en esta misma línea, las cuestiones íntimas, circunscritas a un mundo familiar y hasta cerrado.

El tratamiento en la novela de conformaciones textuales procedentes del periodismo escrito tales como la noticia, la crónica, el reportaje y el testimonio, se realiza en un afán por ensanchar los márgenes de la literatura, ampliar las posibilidades expresivas de la novela y por la necesidad del escritor de acercarse a aquellos sectores sociales de los que, por su propio origen y formación, se había mantenido alejado. Es a través de esta incorporación que se cuestionan los límites de la realidad ficticia con la intención de problematizar la naturaleza canónica del propio género novelístico y del 
cuento pero, sobre todo, de acercar la literatura a un vasto segmento de lectores desfamiliarizados con los géneros tradicionales antes mencionados.

Canto de sirena de Gregorio Martínez se inscribe en este diálogo y nos propone una renovación de la novela incorporando el modo testimonial con el propósito político de revelar las condiciones por las que atraviesan ciertos sectores marginales en el Perú contemporáneo.

En lo que sigue, realizaremos una evaluación del diálogo que Canto de sirena establece con los principios que sustentan los sistemas vinculados con los medios masivos y con la sensibilidad posmoderna.

\section{El nuevo regionalismo de Canto de sirena}

Ángel Rama sostiene (1981) que las grandes visiones integradoras o los complejos panoramas sociales que caracterizaron a la novela del "boom" fueron abandonados por los nuevos novelistas para dar paso a un tipo de novela menos ambiciosa en sus pretensiones y más concentrada en el enfoque de espacios muy delimitados geográficamente. Lo más importante del fenómeno para Rama es que esta nueva narrativa buscaba escapar del tradicional indigenismo para proponerse como una corriente diferenciada en el tratamiento de la conflictividad social.

Aquí es visible apreciar, a partir de ciertos elementos como el lenguaje y la estructura narrativa, una novela no ya provinciana (en el sentido que comporta el ingenuo tratamiento realista naturalista de la realidad), pero sí de la provincia. La representación de estos universos regionales se realiza a partir de un manejo estructural nuevo y de la utilización de un lenguaje cotidiano y hasta desenfadado que es asumido, con total libertad, por un narrador de estirpe popular. Citando a Antonio Cornejo Polar con respecto al nivel técnico que comporta este cambio, se escribe con el "empeño por hacer coincidir la perspectiva del relato con la índole popular de sus referente" (1982: 140).

En efecto, a diferencia de los escritores del primer regionalismo de inicios del siglo XX que implementaban a un narrador ajeno al mundo popular, filiado lingüísticamente a la variedad estándar y al catecismo naturalista, narradores como Gregorio Martínez optan por un lenguaje fuertemente oralizado, caracterizado por el dialecto de la región sur del Perú, por el 
perspectivismo narrativo y la renuncia al causalismo realista.

El enfoque de espacios locales muy concretos y el énfasis en la denuncia ha hecho parecer a esta nueva narrativa como una prolongación del regionalismo de los años veinte, pero no lo es. Marina Gálvez Acero ha incidido bien en estas deudas: "Efectivamente, volvemos a encontrar peculiaridades lingüísticas (en las que se llega a veces a un cerrado localismo), pretensiones costumbristas(...), un honesto afán de denuncia (la violencia de toda índole, como entonces, es el tema por antonomasia) e incluso la semejante candorosa pretensión de dar a conocer una realidad que a pesar de su negatividad guarda todavía como ninguna otra los valores que permitirían una alternativa al modelo de sociedad del presente occidental"(1987: 68). Sin embargo, este nuevo regionalismo ha abandonado, como se veía en las mejores novelas del regionalismo indigenista, el tratamiento explícito y central de los problemas agrarios y los inevitables conflictos por la tierra, para dar paso a una aproximación que privilegia el análisis del conflicto desde una interioridad agraviada, apelando a la exploración en los pliegues de la conciencia, como se puede apreciar en la novela de Gregorio Martínez.

En Canto de sirena estamos frente a una conciencia escritural que ha renunciado a las pretensiones de la totalidad para, desde un pueblo muy localizado, en este caso, Coyungo, al sur de Lima, postular un mundo que es visto desde la parcialidad cultural e ideológica del campesino negro.

Alejado de todo tipo de nativismo exteriorista, Gregorio Martínez consigue con su personaje Candelario Navarro instaurar una conciencia analítica y reflexiva, que se observa a sí misma desarticulada del centro, al margen de una cultura dominante que no comprende y que, por ello, siente ajena. Con ello se acerca a las posibilidades que la técnica narrativa le ofrece en el tratamiento de la interioridad y el tiempo, cuyo decurso se construye sobre la base de la estrategia propia del fragmento, la discontinuidad, las recurrencias y los repliegues narrativos.

De este modo, sin maniqueísmos ideológicos, pero sí con una fuerte conciencia de la problemática social, el nuevo regionalismo de Gregorio Martínez apunta, sobre todo, como sostiene Ángel Rama, “al tratamiento de colectividades marginales en sus diferentes aspectos, desde una modernidad textual atenta e interesada en un flujo comunicativo efectivo, capaz de dar a conocer espacios no tocados o poco frecuentados por una literatura pretendidamente "nacional" (1981). En efecto, el abandono de una narrati- 
va que respondiera a las demandas interpretativas de lo nacional como un concepto indivisible, homogéneo, compacto y armónico, da paso a novelas como Canto de sirena que apuesta por lo regional y lo local, para revelar la problemática integración de amplios segmentos sociales a un centro que no los reconoce o ignora. En ese sentido, el movimiento que la novela de Martínez realiza es político en tanto se constituye en una interpelación al centro del poder, desde los márgenes.

\section{Los géneros del periodismo escrito y Canto de Sirena}

Los nuevos narradores peruanos, herederos del público que los del "boom" ganaron para la literatura, se vieron prontamente absorbidos por las demandas de un mercado que había buscado, en la novela, las respuestas a las grandes interrogantes sobre nuestro continente y su compleja identidad. Sin embargo, en los setenta, ese público empieza a cambiar y los nuevos escritores se ven entregados prontamente a la elaboración de una literatura más asequible a un lector proveniente de las capas medias no intelectualizadas, lector incorporado ya al mercado a través de la masificación de la educación universitaria.

Es el tiempo de las dictaduras instaladas en América Latina, lo que equivale a decir que nuestra narrativa no deja de ser crítica y de luchar contra los poderes instituidos (de hecho Ángel Rama denomina contestatarios del poder a la nueva generación de escritores). El diálogo de la novela con los productos de la cultura de masas permite que esta, como género mayor, asuma otros lenguajes como los del periodismo escrito y el cine. Para algunos del "boom", como Mario Vargas Llosa que advierte el cambio, la solución fue la exploración en la autobiografía y la novela sentimental y el empleo del humor y la sátira ridiculizantes apreciables en La tía Julia y el escribidor y Pantaleón y las visitadoras, respectivamente.

En estos nuevos narradores, como Gregorio Martínez, es visible la necesidad de vincularse con el presente y por lo tanto con las urgencias de una realidad agobiante. Ello los lleva a abandonar el extremo experimentalismo de obras como Cambio de piel de Fuentes o Rayuela de Cortázar para aproximarse a un público más abierto a los productos de la cultura de masas. Si bien la mayoría de los del "boom" atentaron contra las estructu- 
ras tradicionales de la novela, los nuevos se ocuparán de instalar en ella la hibridez narrativa. Ya lo había adelantado la crítica al decir que esta nueva generación de novelistas apuesta por la indefinición narrativa al producir novelas con el semblante de los grandes reportajes al crimen o textos cuyo diálogo con la imagen demandan a un nuevo tipo de lector/observador, capaz de una interpretación más compleja que la puramente textual. Esta hibridez narrativa se explica por la cuestión técnica, pero responde a las necesidades comunicativas con un nuevo público que no solo es el universitario, sino de instrucción escolar y campesino y obrero.

La influencia de los medios masivos de comunicación y el impacto de sus lenguajes en el ámbito de la vida cotidiana, pero sobre todo en la pública, así es evidente desde los años sesenta en el ámbito de América Latina. Frente a esta presencia hegemónica, narradores como Gregorio Martínez se vieron, en cierta forma, desafiados. Es indudable que, en este contexto, los géneros literarios tradicionales (la novela y el cuento) comienzan a perder espacio o a competir, como sostiene Skármeta, con "la elocuencia de los medios masivos de comunicación" (1981: 263).

En lo que toca a la novela, ésta inicia un diálogo provechoso con los géneros de la prensa escrita y la potencia comunicativa de sus modalidades narrativas. Me refiero al testimonio, la crónica, el reportaje y la noticia. Es una experiencia que tiene antecedentes tanto en el "New Journalism" de Tom Wolfe en los Estados Unidos, como en los trabajos antropológicos de Óscar Lewis, cuyas técnicas para la recopilación de la información apelaron a los instrumentos propios de la entrevista periodística. El primero, por romper con el presupuesto de la objetividad en la construcción de la noticia con la consiguiente presencia del punto de vista del periodista-escritor y, el segundo, por sus aportes a la llamada "historia de vida", desde el campo de la antropología social, que sirvió a toda una generación de escritores en el propósito de vincularse con el universo popular-marginal a partir de la encuesta, la entrevista y el registro magnetofónico de la voz.

En el Perú, el Grupo Narración, al que perteneció Gregorio Martínez durante los años setenta, asumió estas modalidades periodístico-narrativas como parte de una posición estético-política que implicó la defensa de los intereses de los sectores mayoritarios de la sociedad. Sus integrantes consideraron, entonces, que el testimonio, el reportaje y la crónica podían constituirse en géneros capaces de servir, con mucha mayor eficacia, al 
propósito de dar cuenta de las luchas populares en el camino de su independencia. De este modo, para Gregorio Martínez, cuya familiaridad con textos como Los hijos de Sánchez de Lewis y Biografía de un cimarrón de Barnet es evidente, el testimonio pasó a convertirse en un medio eficiente en el propósito de dar voz a un personaje representativo de una comunidad campesina del sur del Perú. La necesidad de transmitir un discurso de urgencia, pero que a la vez sea un compendio de la cosmovisión de una comunidad, a partir de la voz de un anciano campesino negro, se convirtió en el eje central de su novela Canto de sirena.

Así, el influjo del periodismo escrito se hace evidente en la ficción cuando de por medio se encuentra el rescate de la inmediatez de un presente que se hace insoportable y cuya gravedad es imprescindible denunciar. Martínez, con su práctica escritural, difumina las fronteras entre el reportero y el escritor, o entre un antropólogo y un escritor. Esa conciencia del manejo artístico de la realidad inmediata fue, sin duda, desarrollada desde la mesa de redacción de un periódico. Pensemos en la labor de Gregorio Martínez como jefe de redacción en el Diario de Marka, periódico de izquierda, durante los años setenta.

Gracias a la influencia de los géneros periodísticos, la narrativa de Martínez cobra velocidad e inmediatez. La presencia de noticias o de breves crónicas en la corriente textual de Canto de sirena, nos sitúan en la vorágine de un tiempo que demanda la participación urgente del lector.

\subsection{El testimonio y la hibridez narrativa en Canto de Sirena}

Con Canto de sirena asistimos a un esfuerzo por renovar los viejos caminos del realismo y sus formas de percepción de la realidad. Martínez privilegia la perspectiva personal que es asumida como eje de la narración e implementa un enunciador múltiple que tiende a la visión fragmentaria, discontinua y, por lo tanto, a la destrucción de la visión autoritaria del narrador omnisciente. Si bien el eje de la narración es el relato del informante Candelario Navarro, en Canto de sirena se incorporan diversas textualidades que conviven con el relato testimonial cuya hibridez se fundamenta en el carácter ficcional del mismo. Es un relato que tiene como base lo contado por Candelario Navarro, pero que es recreado por el autor, Gregorio Martínez, en tanto, como el informante, pertenece al mundo que es referido. La 
hipótesis de la apropiación del discurso de Navarro por parte del autor no le resta independencia al relato.

Si bien la base documental está constituida por la voz del informante real, en este caso Candelario Navarro, esta es ficcionalizada a partir del proceso de escritura a que es sometida. No hablamos, por ello, de una voz real, sino de una fuente de discurso que es manipulada y afectada a través de la lengua literaria inventada por el gestor del testimonio. De hecho, la novela ficcionaliza el universo interior del personaje $y$, para darle corporeidad, se imagina una voz que le dé vida. La novela de Martínez deviene, así, un texto de ficción, pero elaborado bajo los modos y retórica del testimonio. Allí están la espontaneidad, la frescura del lenguaje, la urgencia comunicativa propias del testimonio. La novela no busca ser fiel a los hechos ni a la base documental que la sustenta. No busca ser un documento antropológico, ni reclama un contrato de veridicción a partir del cual se pueda sustentar lo dicho.

La ficcionalización de elementos documentales, como sucede en Canto de sirena, crea, más bien, una nueva forma de registrar la realidad y su presencia enriquece el estatuto de la ficción. Como dice Mirko Lauer, en el contexto de los años setenta se producen "textos más que literarios, simplemente textos de comunicación con el público para llevar un poco más adelante las fronteras de la literatura" (Cornejo et al. 1982: 110).

Desde luego, estamos frente a un nuevo proceso de producción de sentido. No es gratuita la violenta mezcla de géneros, ni el diálogo de la novela con los géneros del periodismo, como tampoco el hecho de que los narradores hayan abandonado la norma estándar y culta del lenguaje para volcarse, como sostiene Rama, "a la conformación de otra, más localista, recogida de las pequeñas tribus urbanas o marginales que empiezan a reclamar su propio espacio" (1981).

\section{Tiempo y lenguaje en Canto de sirena}

Otro de los elementos que caracteriza a esta nueva narrativa es la suspensión de la anécdota o su utilización en una dirección que apunta a otros intereses narrativos. Con ello nos referimos a la suspensión del modo tradicional de narrar articulado a un narrador omnisciente y a la sucesión 
de hechos atados a una relación de causalidad. Desde luego que se narra, pero, como sucede en Canto de sirena, la narración se produce en una línea discontinua con el objeto de inscribir el relato en la repetición y dispersión de hechos y acciones que se viven como un círculo del que no se puede escapar, destinado a mostrar estados o situaciones de postración, marginalidad o abandono.

Canto de sirena busca desintegrar la que podría ser la línea argumental del relato a partir del recurso del fragmento que sirve al propósito de mostrar una realidad desarticulada y marginal. A este recurso se suma el tratamiento del tiempo que, en la novela, borra las marcas de la cronología para tentar a un relato en el que el lector pueda experimentar el estancamiento, una sensación de agobio frente al paso de los días y las horas que no se viven como una experiencia constructiva sino paralizante. Podríamos apelar al concepto de relato acrónico, acuñado por Genette, para describir lo que sucede con el tiempo en la novela de Martínez. Si bien hay un tiempo en el que transcurren los acontecimientos, estos se encuentran absolutamente oscurecidos a la conciencia del propio narrador que no los percibe de forma progresiva sino dispersa. Son hechos que no tienen un marco temporal, ni fecha, y que se mezclan con otros.

De otro lado, frente a la internacionalización de la literatura latinoamericana y sobre todo de su lenguaje, que tiende a la norma estándar, la generación de escritores a la que pertenece Martínez opta, de manera diferente, por una democratización del relato a partir del empleo de un lenguaje acorde con el universo popular o personal al que refiere en sus novelas. Aunque algunos de los escritores del postboom no pertenecen a los universos representados en sus novelas, se realiza el esfuerzo por emplear la norma coloquial o conversacional como una estrategia que busca recuperar la oralidad, por un lado, pero también ser consecuentes con el universo cotidiano en el que transcurren sus historias. Se ha instalado en la novela el imperio de la voz que emplea la escritura como medio para traducir y producir en efecto de la oralidad. Este efecto será central en la conformación del universo representado.

Este esfuerzo, sustentado en un trabajo sobre el lenguaje, constituye un avance en la verdadera construcción de una literatura de índole popular. Este proceso es consecuencia de la definitiva consolidación, a mediados de los sesenta y comienzos de los setenta, de un proceso democrático que em- 
pieza por la expansión de las urbes y que en el plano literario se hace visible con "la adopción franca de ideolectos grupales o de las jergas con los que se expresan tanto las criaturas novelescas como el propio autor, salvando la distancia que los narradores regionalistas establecían entre ellos y sus personajes populares" (Rama, 1981: 26). Ángel Rama sostiene, además, que "la norma más frecuente consistió en la absorción de la historia narrada mediante voces que la desplegaban atendiendo a las peculiares modificaciones del habla, de tal modo que estas decían con igual y a veces mayor precisión lo que las acciones o personajes pretendían decir y en ocasiones no lograban, o consistió en la reducción a su mínima expresión de la distancia existente entre el narrador y lo narrado" (27).

La línea dominante trabajó en la recreación y hasta invención de un lenguaje que se acercara a la vida misma y a su natural manifestación oral. En efecto, además de recoger la replana se insistía en la forja de un lenguaje que expresara de una forma inédita al mundo que se presentaba. La norma estándar quedaba como un instrumento inútil al propósito de referir un universo natural, candoroso, espontáneo, pero sobre todo nuevo para el lector. Para el efecto se alteraba las palabras, el orden de ellas en la oración, se incorporaban neologismos y arcaísmos, se deformaba el sonido del léxico empleado, se recurría a juegos de grafía y hasta se inventaban palabras como es notorio en Canto de Sirena, cuya explosividad lingüística recrea un universo marginal pero lleno de sabiduría popular.

De esta manera, el papel del lenguaje pasaba a ser mucho más activo en la constitución de un universo ficticio, alejado ya del pasado en el que su inexpresiva función normativa lo convertía en un instrumento pasivo. Ahora estamos frente a un narrador inmiscuido inevitablemente en la expresión de su mundo.

En la novela de Martínez, el interés por caracterizar y construir un universo (sus motivos, los personajes, las acciones, la ideología) en su totalidad, a través de la recreación lingüística es central. A partir del montaje lingüístico, esto es, a través de una fusión y mezcla que se opera en el centro mismo de las palabras, Martínez logra renovar el lenguaje literario de la novela en los años setenta. Sumemos a este aspecto relevante en Canto de sirena el que "los rasgos del coloquialismo y la oralidad se funden con los de la tendencia escritural en proporciones indistinguibles" (Duchesne 1984: 194). Este hecho es central para diferenciar a la novela de Martínez 
de las anteriores como Biografía de un cimarrón de Barnett. En Canto de sirena estamos ante una variedad de registros lingüísticos de acuerdo a las necesidades del relato. En algunos se experimenta una mayor dependencia de la norma escrita frente a otros en los que la oralidad y su dinámica dialógica son más evidentes.

De otro lado, en la obra de Martínez es posible observar una dimensión importante del acto que supone la oralización de la escritura. Como en la obra de los narradores orales que buscan en la escritura el registro de las posibilidades expresivas del lenguaje, en Canto de sirena la escritura es un medio que permite el ingreso de la voz del gestor del testimonio. Esta es una estrategia escritural que busca combatir lo efímero de la oralidad. Imprimirle a la voz los rasgos de la escritura se convierte en el único medio de acceder a la permanencia de la voz.

\section{Literatura y compromiso político en Canto de sirena}

En los años setenta, el Grupo Narración, al que perteneció Gregorio Martínez, lanzó una mirada lúcida desde la literatura al campo de la cultura. Su pensamiento se nutrió del marxismo y de un maoísmo incipiente, y, en sus reflexiones sobre el papel de la literatura, los escritores del grupo consideraron que la participación activa de las masas en el proceso del cambio social debía ser el objetivo más importante. Las consecuencias del clasismo político, adoptado posteriormente por algunos integrantes del grupo, nos mostrará el alto grado de politización al que llegaron al tratar de construir un Frente Cultural de carácter eminentemente popular. La identificación del gremio magisterial y el proletariado minero como ejes centrales del cambio social llevó a Narración a privilegiar la lucha política y el aspecto político de la vida en su discurso literario grupal. En esta visión política de la literatura y de su función en el proceso de cambio es indudable la influencia de Marx y Mao, cuyo pensamiento fue el sustento de las principales ideas del grupo. Citemos las siguientes: 1) No existe una práctica artística capaz de obviar el sistema de clases que estructura las sociedades dependientes; 2) Es falso que el arte, en sus diferentes manifestaciones, sea independiente de la dinámica social y de los intereses que los grupos de poder mantienen en sus relaciones con las clases dominadas y 3) Es nece- 
sario formar a través de la obra y de la acción, en la conciencia del pueblo, la necesidad urgente de la revolución.

Reconocida la identidad social del escritor, la mayoría de los narradores de los setenta hizo de la literatura un arma para desenmascarar al poder dictatorial de la época. Conscientes de que en un momento en que las dictaduras ejercían el control del aparato del Estado e incluso de muchos medios de comunicación como sucedió en el Perú con Velasco, la tarea se orientó a desmantelar los procesos mediante los cuales la política ejercía el espejismo del bienestar.

En el prólogo a su libro Novísimos narradores hispanoamericanos en Marcha 1964-1980, titulado "Los contestatarios del poder", Rama hace referencia a que lo nuevo "en estas obras de los jóvenes, aun fluyendo dentro de este cauce grande de la narrativa tradicional, es la rebelión contra todas las formas de poder, su reconocimiento de que se extiende a las más variadas manifestaciones de la vida social y de su cultura, afectando tanto las relaciones sexuales como las estructuras lingüísticas, la organización aparentemente racional del discurso, como las formas legales de la explotación económica, la estructura familiar, como el sistema de clases" (1981: 37).

Esta conciencia del devastador ejercicio de dominación que el poder ejerce en todos los ámbitos de la vida cotidiana será una constante en Canto de sirena a partir de la progresiva toma de conciencia de la marginalidad que atenaza al personaje principal, Candelario Navarro y a su pueblo, Coyungo. La simple elección de un personaje popular sumido en sus propias contradicciones de clase, desde la condición de sujeto desplazado, nos habla del interés del autor por actualizar las demandas de reconocimiento de los segmentos menos favorecidos de la sociedad, presas de la alienación y de una escasa conciencia con respecto al lugar que ocupan en el sistema social. La reivindicación del segmento afroperuano a partir de un lenguaje que subvierte las formas tradicionales de expresión del castellano estándar debe tenerse, así mismo, como un medio a partir del cual se cuestiona el lenguaje del poder.

Desarticulado del centro y atento a las contradicciones de la cultura, Candelario Navarro apela a la cultura letrada para legitimar su propio saber frente a un saber que advierte absurdo irreal. Esta oposición de un saber popular, intuitivo y libre de prejuicios, que se opone al saber oficial es 
capital en la novela para entender los procesos de desmitificación a los que se somete el conservadurismo y sus estrategias de dominación.

\section{Conclusiones}

Canto de sirena sigue los principios de la estética del postboom en el diálogo que establece con los sistemas de comunicación de los medios masivos, en especial con el sistema del periodismo escrito y sus modalidades escriturales. Este diálogo posibilita el ingreso al mundo de la literatura de personajes reales y de una amplia base documental, empezando por la propia vida del informante, Candelario Navarro, que pasa a ser el centro de la atención literaria.

En Canto de sirena la modalidad testimonial opera como un dispositivo que busca consolidar al texto como ficcional, esto es, como una novela propiamente dicha, lejos del documento antropológico. En este proceso quedan, como elementos de la poética testimonial, los recursos propios de la oralidad, la apelación a lo cotidiano, la perspectiva personal, el tono de urgencia y de denuncia con respecto a una situación insostenible. En Canto de sirena todo el sistema general de expresión y composición ha sufrido las alteraciones propias de la ficcionalización literaria.

El nuevo regionalismo de Canto de sirena se visibiliza en la renuncia a la epicidad del indigenismo clásico y en la representación de la conflictividad social desde una conciencia agraviada que observa al mundo a través del fragmento y de una mirada desacralizadora. Si bien la novela sigue situando al personaje afrodescendiente en el campo o vinculado con actividades agrícolas, queda claro que el protagonista es un automarginado que ha decidido alejarse de su comunidad como un penitente que evalúa su vida después de haberse traicionado a sí mismo y a los intereses de su comunidad. En esta dirección la novela trabaja lo popular desde una conciencia agraviada que procesa el decurso de la historia de manera contradictoria. De este modo, si bien la explotación social, a través del sistema de la hacienda costeña, está presente como telón de fondo en la novela, la injusticia generada por este sistema no moviliza al personaje en una lucha frontal. Lo cierto es que, a través de sus propias palabras, el protagonista reconoce haber colaborado con ese sistema, marginando a sus propios 
compañeros o amigos. Así queda configurada la soledad y marginación del personaje principal que se instaura como representante del abandono que el Estado peruano terminó imponiendo a su comunidad.

\section{Referencias}

Cornejo Polar et al. (1982) Literatura y sociedad. Lima: Mosca Azul editores.

Cornejo Polar, Antonio (1982) "Hipótesis sobre la narrativa peruana última”. Sobre literatura y crítica latinoamericanas, Ediciones de la Facultad de Humanidades y Educación Universidad Central de Venezuela, 123-141.

Duchesne, Juan (1984) "Etnopoética y estrategias discursivas en Canto de sirena". Revista de crítica literaria latinoamericana 20, 189-205.

Gálvez, Marina (1987) La novela hispanoamericana contemporánea. Madrid: Taurus.

Rama, Ángel (1981) "Los contestatarios del poder". Prólogo a Novísimos narradores hispanoamericanos en Marcha 1964-198o. México: Marcha editores.

Skármeta, Antonio (1981). "Al fin y al cabo, es su propia vida la cosa más cercana que cada escritor tiene para echar mano". Más allá del "boom": literatura y mercado, Buenos Aires: Folios Ediciones, 263-285. 